\title{
The Relationship between Internet Usage and Perception Self Efficacy and Social Support of Mothers
}

\author{
Suzan Tek (D) \\ Department of Child Health Nursing, Yozgat Bozok University School of Health, Yozgat, Turkey
}

ORCID iD of the author: S.T. 0000-0002-4969-9348.

Cite this article as: Tek S. The Relationship between Internet Usage and Perception Self Efficacy and Social Support of Mothers. Cyprus J Med Sci. 2021; 6(3): 249-254.

BACKGROUND/AIMS

This study was examined the relationship between the internet usage about child health, social support, and self-efficacy perceptions of mothers.

\section{MATERIAL and METHODS}

A descriptive study design was used. The study was conducted in pediatric out-patient clinics of two university hospitals. Totally 484 mothers who had l-3 year-old children were included in the study.

\section{RESULTS}

This study was examined the relationship between the internet usage, social support, and self-efficacy perceptions of parents who have I-3 year-old children according to their sociodemographic characteristics. It is shown that mothers use internet in order to seek information related to their children's health issues. The internet usage is independent of the age of the mother, whereas it is related to the educational levels of the mother and the ages of children. The subjects that are searched by mothers vary according to the ages of their children. The self-efficacy of the mothers is not influenced by the ages of mothers, whereas it is correlated with the educational levels of mothers, ages of the children, and the internet usage. Social support perception is not related to sociodemographic characteristics. However, it is negatively correlated with the internet usage. On the other hand, there is a positive correlation between the social support perception and self-efficacy.

\section{CONCLUSION}

The results are important in order to determine the support requirements of parents and strengthen them. The results can direct nurses and the other health professionals while defining and planning what kind of support should be given to parents.

Keywords: Internet usage, mothers, social support, self-efficacy

\section{INTRODUCTION}

According to the International Telecommunication Union, $51.2 \%$ of the global population use internet by the end of 2018 . When four out of five people use internet in developed countries, internet uptake remains relatively low and four out of five individuals (80\%) are not yet using the Internet in the world's least-developed countries. The internet usage rate of individuals is approximately $65 \%$ in Turkey and $81 \%$ in Cyprus.'

Internet is an efficient, popular, and cost effective tool for parents. ${ }^{2}$ Internet usage provides opportunity to parents to access the information no matter how, when, and where they are. ${ }^{3}$ Increasing number of parents use internet for healthrelated matters ${ }^{4}$ and the internet usage rate among parents is almost $66.0 \%$ in Turkey.' Studies show that parents seek information and social support on the internet. However, there is a limited information related to the subjects and issues that are searched by parents on internet. ${ }^{4-7}$ Majority of the studies are about the parenthood transition on internet usage by parents. ${ }^{3,8-10}$ There are limited numbers of studies about the internet usage of parents on their children's health condition." While transition to parenthood is an important period, first few years after transition to parenthood are also important in terms of information and social support requirements. In the first few years, physiological, psychological, social, and emotional development of children is very fast. In this period, particularly mothers need information and support. However, there is an inadequate research on this issue. $3,9,10$ 
Parents' behaviors for their children are important, because their behaviors influence the health status of the children. ${ }^{12}$ Parenting efficacy relates to the parents' competence and confidence in handling problems related to child rearing. ${ }^{13}$ Parent self-efficacy is defined as the ability to fulfill and organize the parental tasks. Parental self-efficacy is related to the selfcompetence and strength of the person. ${ }^{14}$ It is possible that parents seek information because of their need to strengthen their knowledge and thus their self-efficacy. On the other hand, it is possible that parents use internet since they need both knowledge need and social support. ${ }^{4,5}$ According to the literature review of Plantin and Danabeck, it was concluded that parents use internet more compared to their communication with their families, friends, and acquaintances.

There are a few studies in which the internet usage, social support perception, and self-efficacy of parents in terms of the health issues of their children are examined separately., $8,11,15$ Recent reviews emphasize that there should be studies, which determine the information and support requirements of parents and define the internet usage characteristics of parents in the different stages of parenthood., 46 Therefore, this study was aimed to examine the relationship between the internet usage about child health, social support, and self-efficacy perceptions of mothers who have 1-3 year-old children according to their sociodemographic characteristics.

\section{MATERIAL and METHODS}

A descriptive study design was used. The study was conducted in pediatric out-patient clinics of two university hospitals, in İzmir, Turkey. Totally 484 mothers who had I-3 year-old children were included in the study. The study was included children who did not have chronic disease.

The data of the study were collected by using a sociodemographic characteristics form, internet usage questionnaire, Multidimensional Scale of Perceived Social Support, and SelfEfficacy for Parenting Tasks Index-Toddler Scale. ${ }^{17}$ Sociodemographic form is composed of II questions, which are related to the demographic characteristics such as age and education status of mothers and the age of the children. Internet usage questionnaire is composed of 25 questions related to the internet usage of mothers in the last 12 months about child care. Multidimensional Scale of Perceived Social Support is composed of 12 questions, and it contains family, private, and friend subscales. The Chronbach's $\alpha$ of the scale is 0.50 . The scale contains three groups, which are separately composed of four items. These are

\section{Main Points}

- The mothers use internet in order to seek information related to their children's health issues.

- The internet usage is independent of the age of the mother, whereas it is related to the educational levels of the mother and the ages of children.

- The self-efficacy of the mothers is correlated with the educational levels, the internet usage, and ages of the children.

- Social support perception is negatively correlated with the internet usage. family $(3,4,8$, and II items), friends (6, 7, 9, and 12 items), and private individuals (I, 2, 5, and 10 items). The lowest score which can be obtained from the entire scale is 12 , and the highest score can be 84 . Higher scores reflect the high social support perceptions. Self-Efficacy for Parenting Tasks Index-Toddler Scale is composed of 53 items and seven subscales. It examines the communication between parents and their children when they are between the infancy and childhood period (I-3year old). The total scores that can be obtained from the scale can vary between 53 and 265. Higher scores reflect the strong selfefficacy. There are seven subscales such as emotional competence (seven items), reactivity (eight items), protection (seven items), discipline (Article 9), Games (seven items), teaching (seven items), and daily works-maintenance-configuration (eight items). The Chronbach's $\alpha$ of the scale is $0.91 .^{18}$

The research questions of this study are as follows:

- Is there a relationship between mothers' perception of social support and internet use?

- Is there a relationship between mothers' internet use and self-efficacy perception?

The data were acquired by the researcher in face-to-face interviews, explaining the aim of the research to the parents who were part of the research sampling in the clinics where the research was carried out. Consent was obtained from the parents who agreed to take part in the research. The necessary permission and the approval of the ethics committee (B.30.2.SFÜ.00.50.500/386) were obtained from Sivas Cumhuriyet University in order to conduct the study.

SPSS (Statistical Package for the Social Sciences) for Windows v.l6 (SPSS Inc.; Chicago, IL, USA) statistical program was used to analyze the data of the study. Percentage, mean, t test, Kruskall-Wallis Variance Analysis (KW), chi-square, and correlation analyses were used. The significance was accepted, when $P$ value was lower than .05.

\section{Limitation of the Study}

The generalizability of the results is limited, because this study was done with a limited number of parents who have I-3 yearold children. These research results can be generalized to parents included in sampling.

\section{RESULTS}

The mean age of children is $1.93 \pm 0.83(\mathrm{I}-3), 61.2 \%$ of the children are female, and $38.8 \%$ of them are male. The mean age of the mothers is $31.39+4.18(25-43), 49.8 \%$ of them graduated from university, $51.9 \%$ of them are not working, $79.0 \%$ of them have one child, and $91.0 \%$ of them are using internet every day. The mean duration of the internet usage is $2.15 \pm 0.85$ hours (Table I).

There is no correlation between the age of mothers and the duration of the internet usage, but a negative correlation was found with the child's age. However, the study was detected a significant difference between the educational status of mothers and the duration of the internet usage (Table 2).

According to the results, mothers seek information on internet about child development (32.6\%), breastfeeding (14.7\%), 


\begin{tabular}{|c|c|c|}
\hline Variables & n (\%) & $M \pm S D$ \\
\hline \multicolumn{3}{|c|}{ Child age } \\
\hline One year & $184(38.0)$ & \multirow{10}{*}{$1.93 \pm 0.83(1-3$ years $)$} \\
\hline Two years & $146(30.2)$ & \\
\hline \multirow[t]{2}{*}{ Three years } & $154(31.8)$ & \\
\hline & Child gender & \\
\hline Female & $296(61.2)$ & \\
\hline \multirow[t]{2}{*}{ Male } & $188(38.8)$ & \\
\hline & Child number & \\
\hline One & $382(79.0)$ & \\
\hline Two & $87(18.0)$ & \\
\hline \multirow[t]{2}{*}{ Three } & $15(3.0)$ & \\
\hline & Mother age & \\
\hline $25-29$ year & $200(41.3)$ & $31.39 \pm 4.18$ ( $25-43$ years $)$ \\
\hline 30-34 year & $177(36.6)$ & \\
\hline 35-39 year & $75(15.5)$ & \\
\hline \multirow[t]{2}{*}{$40-45$ year } & $32(6.6)$ & \\
\hline & Education & \\
\hline Primary school & $132(27.3)$ & \\
\hline High school & III (22.9) & \\
\hline University & $24 \mathrm{I}(49.8)$ & \\
\hline \multicolumn{3}{|l|}{ Work status } \\
\hline Employed & $233(48.1)$ & \\
\hline Unemployed & $251(51.9)$ & \\
\hline \multicolumn{3}{|c|}{ Internet usage frequency } \\
\hline \multicolumn{3}{|c|}{$440(91.0)$} \\
\hline Several day in a week & $44(9.0)$ & \\
\hline \multicolumn{3}{|c|}{ Internet usage duration } \\
\hline One hour & $106(21.9)$ & $2.15 \pm 0.85$ \\
\hline Two hours & $238(49.2)$ & \\
\hline Three hours & $100(20.7)$ & \\
\hline Four hours & $40(8.2)$ & \\
\hline
\end{tabular}

weaning (12.0\%), toilet training (12.0\%), and sleeping (II.0\%) (Table 3). There is a significant difference between the subjects that are searched by mothers according to the mean age of children $(P<.005)$. Mothers seek information about the child development for each age group. Mothers who have l-yearold children mostly seek information about breastfeeding, supplementary food, and vaccination; mothers who have 2-yearold children mostly seek information about weaning, toilet training, and safety. Besides, mothers who have 3-year-old children mostly seek information about sleeping, toilet training, discipline, and safety.

There is no significant relationship between the social support perceptions of mothers, the mean age of children, and the mean age of mothers, whereas there is a negative and mild relationship with the duration of the internet usage. There is no significant relationship between the self-efficacy of mothers and the mean age of mothers, whereas there is a positive and

TABLE 2. The Relationship between the Duration of the Internet Usage and Some Demographic Variables

\begin{tabular}{|lccc|}
\hline \multicolumn{1}{|c}{ Variables } & N & $\mathbf{R}$ & $\mathbf{P}$ \\
\hline Mean age of the mothers & 484 & 0.00 & .978 \\
Mean age of the children & 484 & -0.15 & $\mathbf{. 0 0 1}$ \\
Education & $\mathbf{N}$ & $\mathbf{K W}$ & \\
Primary school & $\mathrm{I} 2$ & $235 . \mathrm{II}$ & $\mathbf{1 4 . 1 5 . 0 0 1}$ \\
High school & $\mathrm{III}$ & 207.73 & \\
University & $24 \mid$ & 262.56 & \\
\hline
\end{tabular}

\begin{tabular}{lc} 
TABLE 3. Issues That Are Searched by Mothers \\
\multicolumn{1}{c}{ Issues } & $\mathbf{n}(\%)$ \\
Child development & $158(32.6)$ \\
Breastfeeding & $71(14.7)$ \\
Weaning & $58(12.0)$ \\
Toilet training & $58(12.0)$ \\
Sleeping & $53(11.0)$ \\
Supplementary food & $30(6.2)$ \\
Safety & $30(6.2)$ \\
Vaccination & $15(3.1)$ \\
Discipline & $11(2.3)$ \\
\hline
\end{tabular}

moderate relationship with the mean age of children and negative and mild relationship with the duration of the internet usage. There was not detected a significant relationship between the education status of the mother and the social support perceptions of mothers. On the other hand, there is a significant relationship with the self-efficacy perceptions of mothers (Table 4). There is a positive and significant relationship between the self-efficacy perceptions and the social support perceptions of mothers (Table 5).

\section{DISCUSSION}

This study was conducted in order to determine the relationship between the social support and self-efficacy perceptions of mothers with small children with the internet usage and sociodemographic variables.

All of the mothers use internet, and all of them seek information on internet mostly related to the health of their children. Almost all of them use internet every day and for almost 2 hours. The internet usage rate is higher than the overall rate of the country, and the daily internet usage rate is similar to the overall rate throughout the country. In Turkey, the regular internet usage rate is almost $94.0 \%$. This result is similar to the results of recent studies. Skranes et al." examined the internet usage habits of mothers in case their children are sick, and they showed that almost all mothers seek information on internet. This is due to the easy accessibility to internet and various data can be learnt via internet.

According to the results of this study, the duration of the internet usage is not related to the mean age of mothers. However, as the educational status of the mother increases, the duration of the internet usage decreases. The majority of the studies on the parenthood examine the first years of mothers, and it is detected that mothers need information and seek information on internet. Skranes et al." conducted a study in which they examined the internet usage of parents when their children got sick. According to their study, they showed that mothers with small children believed that they had more lack of knowledge compared to others. There is a negative correlation between the education statuses of mothers and the duration of the internet usage. It is possible that more educated mothers can find the correct keywords and reach the information in a shorter time compared to less educated mothers. The research results support the results of the literature. ${ }^{\|, 19,20}$

According to these results, as the ages of mothers increase, the duration of the internet usage decreases. Meanwhile, mothers still need information related to the health issues of their 
TABLE 4. The Relationship between the Social Support and Self-Efficacy with Some Variables

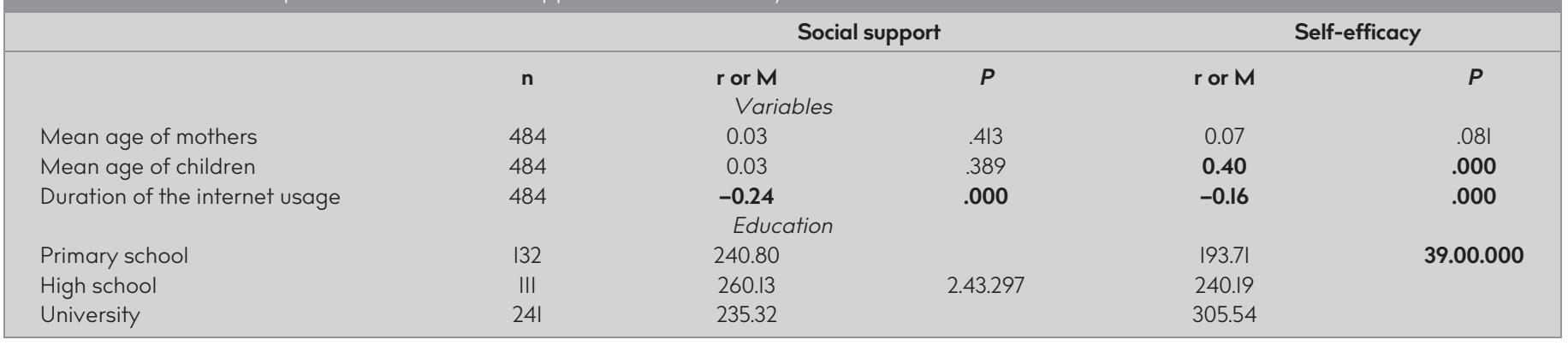

children. As the ages of the children increase, the issues that are searched by mothers on internet change. Mothers with Iyear-old children seek information about the breastfeeding, mothers with 2-year-old children try to find information about the toilet training, and mothers with 3 -year-old children try to learn about the sleeping and toilet training. The child development is the mostly searched topic on internet, because each age period of children requires different developmental characteristics. Nurses and the other health professionals can be involved in the internet services in order to ensure that parents reach the correct information about the health issues. Devolin et al. ${ }^{16}$ conducted a study, in which they examined the requirements of parents who had younger than 6 year-old children. They found that parents needed information mostly about breastfeeding, vehicle safety, child development, and sleeping. However, the study is the first one which shows the subjects searched by mothers and indicates the relationship between these subjects and the ages of children. It is well known that mothers still need information. Therefore, these results are important to direct nurses and the other health professionals to be involved in the internet health services in order to ensure parents to reach the correct information. In this study, mothers were not asked about the web sites from where they searched information. The study does not know whether mothers use formal websites of health professionals or governmental web sites. On the other hand, there are known that parents still need information and the subjects that they seek on internet vary as their children grow up. Nurses and the other health professionals can direct parents in this regard.

The self-efficacy of the mother is not affected by mother's age, whereas it is influenced by the child's age. The self-efficacy scores of mothers who have older children and higher educational levels are higher compared to others. Similarly, there are studies which show that the age of the mother does not affect the self-efficacy of parents," while there are some other studies which indicate that the age of the mother is a strong predictor for the self-efficacy of the mother. ${ }^{21}$ Mothers have less knowledge in the first years of the parenthood. The efficacy level increases as one gains knowledge and experience about something. Self-efficacy refers to an individual's evaluation of his / her ability to successfully complete a task in a given situation. Self-efficacy has been found to be an important component of

\begin{tabular}{|c|c|c|c|}
\hline Variables & $\mathbf{n}$ & $r$ & $P$ \\
\hline Social support self-efficacy & 484 & .18 & .000 \\
\hline
\end{tabular}

performing or learning diverse human behaviors, desirable or undesirable. ${ }^{22}$ Consequently, parenthood should be accepted as a new life style and self-efficacy levels increase as time passes. It has been found that parenthood self-efficacy is a mediator for parents with older children and higher education levels, and it affects the health parental behaviors. ${ }^{18}$ Salonen et al. ${ }^{23}$ examined the effects of internet based education on the self-efficacy levels of parents, and they observed increased self-efficacy levels both in intervention and control groups. The lack of difference between two groups can be due to the increased self-efficacy experiences of parents related to the ages of children. This can be related to the increase in the mother's adaptation to parenthood or increased knowledge of parenthood. According to the study results, the self-efficacy perceptions of mothers with healthy children increase as the children grow depending on the increased knowledge and experience. Besides, there is also detected that the duration of the internet usage of them decreases as the self-efficacy levels of mothers increase. The self-efficacy of parents with sick children was examined in one of the studies, and it was shown that the self-efficacy levels increased as parents reached the correct information. Nieuwboer et al. ${ }^{24}$ conducted a meta-analysis study and showed that the internet support was very important for parents. It was shown that planned support web sites increased the self-efficacy of parents. The study is not an interventional study, but it was shown that parents try to find information on internet and thus this positively affects their selfefficacy levels and perceptions.

In the study, the social support perception of the mother is not related to the education status of the mother and the age of the children. However, it is negatively correlated with the internet usage. As the social support increases, the duration of the internet use decreases. This result supports the studies, which show that mothers seek social support on the internet. Even though there are studies which indicate that there is no relationship between the social support perception and internet usage, some other studies show that parents seek and provide social support on the internet and they also provide the information in the internet. $^{4-6}$ Parents share their knowledge and experiences with others, and they give suggestions to less experienced parents via internet. Therefore, social support and the internet usage are related to each other. Some studies show that mothers interact with other parents on the internet more than interacting with their own family and friends. This study contains the social support perception scale and family, friend, and private person subscales. It can be concluded that as the scores obtained from these scales increase, the social support perception positively increases. As the support from the family, friend, or private person increases, the social support requirement decreases. 
These results are contradictory to results of some studies. 9,25 These different results can be due to the cultural features of societies or because of the experiences of mothers related to the first 12 months of the parenthood. The family and relative interactions are important in social support in Turkish society. Devolin et al. ${ }^{16}$ found that family and friends were among individuals who support parents. Social sources are important for parents in order to successfully adapt to the parenthood. Face to face interactions with the family, friends, and other members of the society are important support sources for parents. ${ }^{26}$

There is a positive and significant relationship between the social support perceptions and self-efficacy of mothers. The self-efficacy of parents has a mediator role between the motherhood experience and the social support. Studies, which are related to the first years of the parenthood, show that social support positively affects the self-efficacy of parents. ${ }^{3}$ The study results support the literature, and meanwhile, the study is the first one which indicates the relationship between the social support and the self-efficacy of parents in the next years of the parenthood. This study results can be used to strengthen the self-efficacy of parents in later years of parenthood by increasing the effects of social support.

In conclusion, this study was examined the relationship between the internet usage, social support, and self-efficacy perceptions of parents who have l-3 year-old children according to their sociodemographic characteristics. It is shown that mothers use internet in order to seek information related to their children's health issues. The internet usage is independent of the age of the mother, whereas it is related to the educational levels of the mother and the ages of children. The subjects that are searched by mothers vary according to the ages of their children. The self-efficacy of the mothers is not influenced by the ages of mothers, whereas it is correlated with the educational levels of mothers, ages of the children, and the internet usage. Social support perception is not related to sociodemographic characteristics. However, it is negatively correlated with the internet usage. On the other hand, there is a positive correlation between the social support perception and self-efficacy. The study results are important in order to determine the support requirements of parents and strengthen them. In this regard, the results can direct nurses and the other health professionals while defining and planning what kind of support should be given to parents.

Results of studies in which fathers are not involved can be even more beneficial. In further studies, the websites which are used by mothers can be examined. This study was examined the internet usage of mothers whose children are I-3year-old in the last 12 months. It is also possible to examine the association between the internet usage and the knowledge and support requirements of parents in later childhood periods. The relationship between the internet usage and the social support perception is examined in the study. Furthermore, effects of social media on this relationship can further be examined.

Ethics Committee Approval: Ethics committee approval was received for this study from Sivas Cumhuriyet University (approval date: May 7, 2016, approval number: B.30.2.SCÜ.00.50.500/386).

Informed Consent: Written informed consent was obtained from all participants who participated in this study.
Peer-review: Externally peer-reviewed.

Conflict of Interest: The author has no conflicts of interest to declare.

Financial Disclosure: The author declared that this study has received no financial support.

\section{REFERENCES}

I. Sanou B. Measuring the information society report. International Telecommunication Union, 2018. Available at https://www. itu.int/en/ITU-D/Statistics/Pages/stat/default.aspx (accessed date 25 June 2019).

2. Walsh AM, Hamilton K, White KM, Hyde MK. Use of online health information to manage children's health care: A prospective study investigating parental decisions. BMC Health Serv Res. 2015;15:131. [CrossRef]

3. Shorey S, Wai-Chi SC, Chong YS, Hong-Gu H. Maternal parental self-efficacy in newborn care and social support needs in Singapore: A correlational study. J Clin Nurs. 2014;23(15-16):2272-2283. [CrossRef]

4. Daneback K, Plantin L. Research on parenthood and the internet: Themes and trends. Cyberpsychology. 2008;2(2):70I-707.

5. Plantin L, Daneback K. Parenthood, information, and support on the internet: A literature review of research on parents and professionals online. BMC Fam Pract. 2009;10:34. [CrossRef]

6. Walker SK, Dworkin J, Connell JH. Variation in parent use of information and communications technology: Does quantity matter. Fam Consum Sci Res J. 2011;40(2):106-I19. [CrossRef]

7. Dworkin J, Connell J, Doty J. A literature review of parents' online behavior. Cyberpsychology. 2013;7(2):Article I. [CrossRef]

8. Bernhardt JM, Felter EM. Online pediatric seeking among mothers of young children: Results from a qualitative study using focus groups. J Med Internet Res. 2004;6(I):e7. [CrossRef]

9. Madge $\mathrm{C}, \mathrm{O}^{\prime}$ Connor $\mathrm{H}$. Parenting gone wired: Empowerment of new mothers on the internet. Soc Cult Geogr. 2006;7(2):199-220. [CrossRef]

10. Radey M, Randolph KA. Parenting sources: How do parents differ in their efforts to learn about parenting. Fam Relat. 2009;58(5):536548. [CrossRef]

II. Skranes LP, Lohaugen GC, Botngard A, Skranes J. Internet use among mothers of young children in Norway-A survey of internet habits and perceived parental competence when caring for a sick child. J Public Health. 2014;22(5):423-43I. [CrossRef]

12. Chung SJ, Bang K. Parenting efficacy and health-promoting behaviors for children of mothers from native and multicultural families in Korea. Asian Nurs Res. 2015;9(2):104-I08. [CrossRef]

13. Johnston C, Mash EJ. A measure of parenting satisfaction and efficacy. J Clin Child Psychol. 1989;18(2):167-175. [CrossRef]

14. Leahy-Warren P, McCarthy G, Corcoran P. First-time mothers: Social support, maternal parental self-efficacy and postnatal depression. J Clin Nurs. 2012;2I(3-4):388-397. [CrossRef]

15. McDaniel BT, Coyne SM, Holmes EK. New mothers and media use: Associations between blogging, social networking, and maternal well-being. Matern Child Health J. 2012;16(7):1509-1517. [CrossRef]

16. Devolin $M$, Phelps $D$, Duhaney $T$, et al. Information and support needs among parents of young children in a region of Canada: $A$ cross-sectional survey. Public Health Nurs. 2013;30(3):193-201. [CrossRef]

17. Zimet GD, Powell SS, Farley GK, Werkman S, Berkoff KA. Psychometric characteristics of the multidimensional scale of perceived social support. J Pers Assess. 1990;55(3-4):610-617. [CrossRef]

18. Coleman P, Karraker K. Maternal self-efficacy beliefs, competence in parenting, and toddlers' behavior and developmental status. Infant Ment Health J. 2003;24(2):126-148. [CrossRef] 
19. Fox $\mathrm{S}$, Jones $\mathrm{S}$. The social life of health information. Pew internet $\delta$ American life project. 2009. Available at http://www.pewinter net.org/files/oldmedia/Files/Reports/20II/PIP_Social_Life_of_ health_Info.pdf (accessed date 25 June 2019).

20. Khoo K, Bolt P, Babl FE, Jury S, Goldman RD. Health information seeking by parents in the internet age. J Paediatr Child Health. 2008;44(7-8):419-423. [CrossRef]

21. Jones TL, Prinz RJ. Potential roles of parental self-efficacy in parent and child adjustment: A review. Clin Psychol Rev. 2005;25(3):341-363. [CrossRef]

22. Bandura A, Schunk DH. Cultivating competence, self-efficacy, and intrinsic interest through proximal self-motivation. J Pers Soc Psychol. 1981;4I(3):586-598. [CrossRef]
23. Salonen $A H$, Kaunonen $M$, Astedt-Kurki $P$, Jarvenpaa $A L$, Isoaho $H$, Tarkka MT. Effectiveness of an internet-based intervention enhancing Finnish parents' parenting satisfaction and parenting self-efficacy during the postpartum period. Midwifery. 2011;27(6):832-84l. [CrossRef]

24. Nieuwboer CC, Fukkink RG, Hermanns JM. Online programs as tools to improve parenting: A meta-analytic review. Child Youth Serv Rev. 2013;35(II):|823-I829. [CrossRef]

25. O'Connor H, Madge C. My mum's thirty years out of date: The role of the internet in the transition to motherhood. Community Work Fam. 2004;7(3):351-369. [CrossRef]

26. Drentea P, Moren-Cross JL. Social capital and social support on the web: The case of an internet mother site. Social Health IIIn. 2005;27(7):920-943. [CrossRef] 